\title{
Корпоративная культура как фактор эффективности инновационной деятельности и роста инновационного капитала
}

\author{
Первакова Е.Е. ${ }^{22}$, Золотова М.С. ${ }^{23}$
}

Статья посвящуена описанию способов влияния корпоративной культуры на эфррективность инновачионной деятельности $u R \& D$ затрат организации, а также принцииов построения инновачионной компании. $B$ работе приводятся результатьл эмпирического исследования авторов о приоритетности различных факторов корпоративной культуры для поддержки инновационного поведения сотрудников.

JEL: M54

Ключевые слова: горпоративная культура, инновационная организаџия, инновационная стратегия, эффективность $R \& D$-затрат

Один из классических подходов к изучению влияния корпоративной культуры на эффективность деятельности компании и ее стоимость заключается в рассмотрении корпоративной культуры в качестве составляющей ее интеллектуального капитала.

В данной концепции корпоративная культура представляет собой нематериальный актив организации, которые повышает стоимость бизнеса и нуждается в инвестициях (Shultz, 1968). В наиболее современных работах (Ивашковская 2009, Байбурина, 2007) корпоративная культура рассматривается как субкомпонент подсистемы процессного капитала, который создает благоприятные условия для реализации человеческого капитала.

Влияние корпоративной культуры на потенциальный рост стоимости осуществляется в трех направлениях: в росте трудовой мотивации и вовлеченности сотрудников в процесс труда, в росте репутации компании как работодателя и в совершенствовании этики общения с клиентами и партнерами (Первакова, 2012). Это приводит к увеличению производительности, лояльности сотрудников и партнеров, инновационной активности и эффективности. Таким образом, можно говорить о влиянии корпоративной культуры на другие компоненты интеллектуального капитала - инновационный капитал и партнерский, сетевой капитал. Изучение влияния корпоративной культуры на инновационную эффективность и инновационный капитал организации является целью данной работы.

Эффективность инновационной деятельности является одной из ключевых характеристик управления компании в современной постиндустриальной экономике. Существует большое количество факторов, которые делают компанию по-настоящему инновационной: инновационная стратегия, лидерское ведение бизнеса, глубокое понимание клиента, талант сотрудников. Однако более важным, чем любой из перечисленных элементов по отдельности, является корпоративная культура - множество паттернов поведения, смыслов и ценностей, свойственных членам данной организации.

Согласно опросу 600 топ-менеджеров ведущих мировых инновационных компаний (Jaruzelski, 2011), важнейшим фактором эффективности инновационных затрат является поддержка инновационной стратегии со стороны корпоративной культуры. По мнению участников исследования, способность к риску, креативность, открытость и сотрудничество являются критичными для достижения успеха в глобальной инновационной экономике. В то же время только 47\% опрошенных топ-менеджеров заявили о соответствии корпоративной культуры своих компаний инновационной стратегии высшего руководства.

Обращаясь к истории вопроса, надо сказать, что в конце XX века концепция

\footnotetext{
22 Доцент кафедры экономики и финансов фирмы НИУ ВШЭ.

${ }^{23}$ Студентка 5-го курса факультета экономики НИУ ВШЭ.
} 
корпоративной культуры прочно завоевала одно из ведущих мест в литературе по теории организации благодаря трудам известных зарубежных исследователей Хофстеде, Роббинса, Куинна, О’Рэйли, Дэнисона. Существенный вклад в изучение теории влияния корпоративной культуры на эффективность бизнеса и особенности формирования российской корпоративной культуры внесли отечественные ученые Т.Ю. Базаров, В.А. Спивак, В.Д. Козлов, М.Н. Павлов, В.Н. Воронин, И.Д. Ладанов.

Тема влияния корпоративной культуры на инновационную активность стала активно рассматриваться в трудах зарубежных ученых во второй половине 90-х годов прошлого века.

Наибольшее значение предавалось такому фактору корпоративной культуры, как стиль лидерства (Cooke, 2000). Основное внимание уделялось методам материального и психологического стимулирования сотрудников, а также созданию организационных структур для поддержки инноваций, выделению инновационных бюджетов.

Некоторые авторы полагают, что поддерживающий, участливый, демократический и ориентированный на сотрудничество стили лидерства эффективны для роста инновационной организации, что сильный, авторитарный лидер сдерживает инновации (Janis,1982). По мнению других исследователей (King, 1995), сильная власть способствует авторитету лидера, цельности корпоративной культуры, в рамках авторитарного управления может существовать конкуренция между сотрудниками, которая при умелом управлении будет способствовать инновациям.

На наш взгляд, наиболее адекватным теоретическим подходом к описанию инновационного лидерства является концепция «трансформирующего» лидера (Jaskyte, 2004). Трансформирующий лидер ориентирован на будущее, открыт, динамичен, использует методы стратегического планирования. При твердом поддержании своего авторитета, он, тем не менее, позволяет сотрудникам выдвигать и реализовывать собственные идеи. Они использует харизму, воодушевление и интеллектуальную стимуляцию, чтобы поощрять креативность сотрудников. Теория трансформирующего лидерства определяет пять основных практик поощрения инноваций:

- избегание обычных путей;

- создание общего видения среди сотрудников;

- предоставление сотрудникам возможности действовать в соответствии со своим видением;

- моделирование путей выполнения задач;

- поощрения сотрудников посредством признания их достижений.

В конце XX века получил развитие предложенный ранее альтернативный подход к рассмотрению роли лидера в инновационной активности организации. Сторонники данного подхода предполагают (Hannan, 1984), что было бы упрощенным считать, что инновационность организации определяется предпочтительно лидером, поскольку лидерство является субъективным феноменом и элементы внешней среды могут существенно исказить видимые эффекты лидерства. Таким образом, при изучении влияния корпоративной культуры на эффективность инновационной деятельности организации необходимо учитывать существенно большее количество факторов, чем стиль лидерства.

Многие исследователи считают, что наиболее важны миссия, ценности, убеждения членов организации, а также степень налаженности горизонтальных и вертикальных взаимодействий. Лидер может способствовать развитию путем создания новых областей общих ценностей, например поощрения риска и креативности.

Новейшие исследования посвящены рассмотрению концепции инновационной организации. Авторы концепции исходят из убеждения, что для высокой инновационной активности в компании недостаточно только обеспечения структуры для выдвижения идей, инновационной стратегии руководства и наличия сотрудников-инноваторов. Необходимо также обеспечить особую инновационную среду для поддержания креативности и разделения идей.

Рассмотрим прежде всего фактор внутренней коммуникации. Классический подход к 
корпоративной инновационности рекомендует максимально исключить бюрократию, различные контролирующие структуры, снизить коммуникационные барьеры, мешающие распространению новых идей. Опыт реальных компаний говорит о том, что подобные преобразования необходимо производить с осторожностью, чтобы не ввергнуть организацию в хаос (Heskett, 2012). Успешные инновационные компании используют инструменты и технологии, балансирующие формальные и неформальные элементы управленческой структуры. Личная и командная конкуренция допускается в ограниченных пределах. Необходима кооперация между отделами и командами внутри компаний. Не менее важна хорошая коммуникация подчиненных и начальников, эффективная организация внутри команд. Необходима общая материальная заинтересованность всех членов организации в эффективном внедрении инноваций.

Следующей темой обсуждения являются ценности и убеждения членов организации, которые составляют ядро корпоративной культуры.

Теоретические работы в области инновационных ценностей концентрируют внимание на обеспечении моральной поддержки и вдохновения инноваторов. Отрицается обвинительная корпоративная культура, в которой зачинщиков неудачных проектов делают козлами отпущения, предлагается рассматривать ошибки как возможность обучения и развития компании. Некоторые компании пытаются выстраивать корпоративную историю как историю успехов отдельных сотрудников, вносивших новые предложения и продвигающих компанию вперед. В качестве основного мотивирующего фактора рассматривается желание человека «оставить след в мире» и получить признание со стороны коллег и начальников (Steers,2010).

Однако изучение успешного опыта крупнейших инновационных корпораций мира выводит на первое место другие факторы создания инновационного климата (Jaruzelski, 2011). Важнейшими корпоративными ценностями представители подавляющего большинства успешных зарубежных инновационных компаний считают:

1. Сильную связь с покупателями. Это подразумевает не только ориентацию на клиента в обычном смысле слова, но и включение потребителя в сам процесс разработки инновации, изучение и активное формирование его потребностей, учет мнения потребителей в процессе выбора вариантов и отладки образцов продукции.

2. Гордость за свой продукт и свою компанию. Остановимся далее на способах организации труда и структурах поддержки инновационного климата и внутреннего предпринимательства.

В последнее время наибольшее внимание уделяется необходимости выделения определенного количества рабочего времени и определенного лимита финансовых средств для реализации собственных идей сотрудников, экспериментирования и творчества. Действительно, инновационные корпорации демонстрируют высокий уровень доверия к сотрудникам и реализуют принципы разнообразия, командности и доступности идей в условиях специальных кампусов.

Однако более тщательное изучение опыта успешных инновационных компаний (Heskett, 2012) позволяет дополнить данные установки условиями их эффективности:

- Тщательный, обдуманный выбор сотрудников, которые занимаются формированием корпоративных инновационных ценностей.

- Выбор и приглашение людей, которые обладают не только профессиональным опытом, но и индивидуальной инициативой использовать выделяемые деньги и временные ресурсы для реализации своих проектов согласно общим целям организации, а также «продавать» результаты своих проектов руководству и другим членам организации; сотрудники инновационной компании должны обладать креативностью, способностью применения нестандартного, порой парадоксального подхода, быстрой адаптивностью в бизнес-среде, системным анализом имеющихся взаимосвязей, преград и проблем, целостным концептуальным видением стратегии, эффективной самоорганизацией, способностью управлять мотивацией команд. 
- Особая стратегия создания творческих коллективов из сотрудников с различным опытом и базовым образованием, которые могли бы обеспечить внедрение идей на коллективной основе. Важнейшими способами поддержки инновационного духа является обсуждение с сотрудниками целей и видения, поддержание их вовлеченности в инновационный процесс. Для этого цели компании должны быть ясными и согласовываться с общей миссией компании, т.е. общей целью деятельности с точки зрения общественной пользы.

В последние годы в деловом сообществе творчество сотрудников воспринимается как стандартный инструмент бизнеса. Ведущие мировые корпорации, например Toyota и Kawasaki Engineering, получают более двух миллионов инновационных предложений в год, большая часть которых посвящена улучшению качества продукции и снижению производственных затрат. Такая степень вовлеченности сотрудников обеспечивается прежде всего двумя факторами.

- Продуманной системой материального стимулирования авторов инновационных идей и всех членов организации, успешно внедряющих инновации.

- Наличием специальной инфраструктуры поддержки инноваций.

К первому фактору относятся гибкие системы выплаты премий и бонусов, включающие процент прироста выручки от рыночной реализации новых товаров или снижения затрат компании, а также различные формы участия инноваторов в собственности компаний. Возможны также формы создания собственных дочерних бизнесов авторов инновационных предложений с долевым участием корпорации.

Ко второму фактору относится организация системы рассмотрения, отбора и поддержки инновационных предложений. Практикуется организация инновационных комитетов, регулярно рассматривающих инновационные предложения сотрудников, выделение инновационных фондов, организация инновационных совещаний сотрудников. Bce эти формы инновационной поддержки должны быть обеспечены материальной инфраструктурой, например, отдельными комнатами, где могли бы проходить подобные совещания, и комнатами для индивидуальной концентрации.

Поскольку процесс внедрения инноваций связан с изменениями в организации, необходимо преодолевать сопротивления изменениям. Для этого проводится разъяснительная работа с сотрудниками для снижения страха потери работы или чрезмерной перегрузки. Необходимо создание открытой атмосферы обсуждения происходящих перемен, которая снижает волнение и ощущение неопределенности. В случае успешного внедрения инноваций все косвенные участники процесса должны получить материальное и моральное поощрение.

Важнейшим фактором роста инновационной активности организации является вовлеченность клиентов в процесс создания инноваций. Творчество свойственно не только производителям, но потребителям. Вовлечение клиентов в инновационный процесс важно по двум причинам:

- клиенты действительно могут внести ценные предложения по совершенствованию производимых для них продуктов;

- новые продукты и услуги будут лучше восприниматься клиентами, если они сами принимали участие в их разработке.

При этом успешные инновационные компании обращаются к наиболее активным клиентам из базы пользователей, организовывают фокус группы для выдвижения идей, тестирования входного дизайна и параметров разработок. Широко используются также добровольные группы пользователей, которые занимаются тестированием новых продуктов, например Linux, Apple-платформы. Интернет сделал доступным легкие контакты с больших количеством пользователей в режиме управляемых интернет-сервисов. Примером является платформы «Адидас» и «Лего», которые позволяют пользователям своих сайтов создавать собственные кроссовки и игрушки. Создаются даже виртуальные инновационные агентства, на которые фиксируются и рассматриваются идеи пользователей. На них можно 
сформулировать сложные задания и проблемы, которые будут решаться большим количеством участников-пользователей. Интересным феноменом являются сети инноваций. Они дают возможность диверсифицировать риск и получить доступ к базам знаний и опыта вне конкретной организации. Различают предпринимательские сети (расширение возможностей на основе дополнения услуг и ресурсов), общества практиков (отдельные сотрудники разных организаций, связанные различными интересами), пространственные кластеры, обучающие сети, сети изучения стандартов и другие (Bessant, 2009).

Для оценки существующего сетевого потенциала компании необходимо ответить на следующие вопросы:

1. Имеет ли организация налаженные связи с внешними ресурсами знаний, такими как университеты, исследовательские центры, специализированные агентства?

2. Позволяет ли подход к управлению обеспечить решение стратегических исследовательских задач?

3. Практикуются ли «открытые инновации» с использованием широких внешних контактов, которые давали бы постоянный поток решенных проблем?

Следующим фактором поддержания инновационного климата является правильное измерение инновационной эффективности и успешности инноваций. Среди ключевых показателей эффективности инновационной деятельности должно быть:

- число идей, сгенерированных на начальном этапе;

- количество неудач на стадии развития инноваций и этапе выхода на рынок;

- процент превышения времени и бюджета при разработке инноваций;

- среднее время выхода на рынок новой разработки по сравнению с отраслевыми аналогами.

Таким образом, измерение инновационной эффективности направлено на выявление степени интенсивности инновационного процесса с учетом затрат на его проведение. Измерение успешности инноваций делает акцент на выявлении того, в какой степени инновационный процесс полезен для бизнеса компании. Рассматривается экономический эффект от внедрения инноваций, выраженный в росте финансовых показателей и лояльности клиентов. Измерение инновационной эффективности в организации в целом необходимо дополнить изучением инновационной результативности отдельных менеджеров.

Важнейшим отличием инновационной организации являются постоянные инвестиции в обучение персонала. При этом не только руководители организации понимают необходимость постоянного повышения квалификации своих сотрудников, но и сами сотрудники, включая руководителей, заинтересованы в обучении.

Обучение помогает сотрудникам реагировать на инновационный опыт, побуждает к экспериментированию, способствует распространению идей внутри компании. При этом цели и способы обучения сотрудников также должны быть современными и инновационными.

Мы предлагаем концепцию инновационного обучения менеджеров компании, апробированную нами в форме «Корпоративного инновационного университета» (Ляпина, 2009). Суть инновационного обучения заключается в выборе руководством и менеджерами компании инновационных идей и разработке бизнес-проектов их реализации. Целью обучения является развитие творческого потенциала и формирование предпринимательских компетенций менеджеров, таких как видение собственной перспективы развития в рамках компании, превращение проблемы организации в идею инновационного развития, способность презентовать свои идеи «покупателям бизнес-эффектов», т.е. топ-менеджерам и собственникам компании, умение мотивировать других сотрудников для работы в инновационной команде. Другим важным результатом инновационного обучения являются готовые к реализации бизнес-проекты и инновационные команды.

Обучение по программе инновационного университета проходит в несколько этапов. На первом этапе производится специальный отбор инициативных сотрудников из числа менеджеров и кадрового резерва компании. На втором этапе производится совместное 
обсуждение реальных проблем бизнеса, трансформация их в идеи для инновационных проектов и выбор наиболее интересных идей для разработки в ходе обучения, а также формирование бизнес-команд из участников обучения для разработки проектов. На третьем этапе происходит обучение участников по курсу «Предпринимательские технологии», а также разработка концепций выбранных бизнес-проектов. На четвертом этапе участниками обучения осуществляется сбор данных и коммерческая оценка эффективности и риска своих бизнес-проектов, а также презентация результатов разработки на предпринимательском комитете высшему руководству и собственникам компании. Лучшие проекты утверждаются к реализации и получают соответствующие материальные, временные и трудовые ресурсы.

Особого внимания заслуживает проблема финансирования инновационной деятельности. В период с 2005 по 2010 год международная консалтинговая компания Booz \& Company's провела исследование 1000 публичных компаний по всему миру, которые имели самые большие затраты на научные исследования и развитие (Jaruzelski, 2011).

По каждой компании был собран полный набор финансовых результатов, включая объем продаж, прибыль от основной деятельности, чистую прибыль, затраты на науку и развитие в ретроспективе, рыночную капитализацию, а также объем дивидендов. Все компании были отнесены в одну из 9 отраслей и один из пяти регионов. Расходы на научные исследования и развитие были нормированы в зависимости от среднеотраслевых значений, полученных по данным Мирового Банка и Международного валютного фонда.

По результатам исследования стало очевидно, что не существует прямой статистической корреляции между количеством средств, потраченных на исследования и развитие (инновационные расходов) и финансовыми результатами компаний.

Многие ведущие компании, например Apple, регулярно не израсходовали запланированные на инвестиции ресурсы, при этом существенно опережая конкурентов по росту прибыли, дохода и рентабельности собственного капитала. В то же время целые отрасли, такие как фармацевтика, постоянно тратили огромную часть финансовых ресурсов на инновации, имея значительно меньшие результаты, чем хотелось бы менеджерам и акционерам.

Опрос топ-менеджеров успешных инновационных компаний позволит выявить, что наряду со степенью инновационности корпоративной культуры важное значение имеют такие факторы, как правильное распределение инновационных финансовых ресурсов. Можно выделить три основные характеристики эффективного распределения затрат на инновационную деятельность:

1. Венчурный характер финансирования. В организации должно быть профинансировано достаточно большое количество рискованных проектов, лишь небольшой процент которых приводит к существенному успеху. Однако крупных проектов не должно быть слишком много, чтобы не создавать конкуренцию за ресурсы внутри организации

2. Равномерное распределение средств между краткосрочными, среднесрочными и долгосрочными проектами. Опыт наиболее успешных компаний говорит о том, что примерно 1/3 часть инновационных затрат должна приходиться на разработки, дающие экономический эффект в течение года, $1 / 3$ - на развитие текущих продуктов с перспективой на 2-5 лет и $1 / 3$ - на фундаментальные исследования, результаты которых можно ожидать не ранее чем через 10 лет.

3. Вознаграждение авторам и разработчикам инновационной идеи должно представлять собой предпринимательский процент от внедрения инновации.

Предельным выражением корпоративной культуры инновационного типа является «креативная корпорация» (Колобов, 2007). Основными ее чертами является:

- перенос акцента с отдельных производственных операций на процесс создания продукции в целом;

- главной задачей инноваций является не модификация продукта, а изменение процесса его создания;

- деятельность является более скоординированной с точки зрения достижения единой 
цели и более автономной и индивидуальной с точки зрения конкретного работника;

- процесс принятия ответственных решений переносится на максимально возможный нижний уровень;

- в организации возникают небольшие мобильные коллективы единомышленников, объединенными общими задачами и общими ценностями;

- рост компетенций высшего звена управления происходит существенно быстрее роста компетенций среднего звена.

Креативная корпорация может трансформироваться в сеть предпринимателей.

Миссией креативной корпорации является развитие личности ее создателей и сотрудников.

Следующая часть статьи будет посвящена описанию результатов пилотного исследования мнений российских собственников и менеджеров о влиянии факторов корпоративной культуры на эффективность инновационной деятельности бизнеса. Исследование проведено авторами статьи при поддержке сотрудников отделения национальной экономики экономического факультета АНХ и ГС.

На первом этапе исследования (2009-2010) был проведен ряд глубинных интервью и фокус-групп с собственниками, менеджерами и специалистами по управлению персоналом для определения основных барьеров инициации и реализации инноваций в российских компаниях, а также выявлению набора факторов корпоративной культуры, которые оказывают наибольшее влияние на инновационную активность сотрудников организации (Первакова, 2012). В результате первого этапа был определен перечень из следующих 13 факторов корпоративной культуры (табл. 1).

Таблица 1

\begin{tabular}{|c|c|c|c|}
\hline № & Фактор & $\begin{array}{c}\text { Характер и способ влияния } \\
\text { (проявления) }\end{array}$ & Комментарии \\
\hline 1. & $\begin{array}{l}\text { Прозрачность } \\
\text { целей }\end{array}$ & $\begin{array}{l}\text { Сотрудник понимает и принимает } \\
\text { миссию своей компании, т.е. цель } \\
\text { компании с точки } \\
\text { общественной пения } \\
\text { которую его компания, пригосит } \\
\text { обществу }\end{array}$ & $\begin{array}{lr}\text { Необходимо отметить, что } \\
\text { миссия } & \text { декларирует } \\
\text { именно } & \text { общественную } \\
\text { пользу, без } & \text { упоминания } \\
\text { выгод } & \text { конкретного } \\
\text { человека } & \end{array}$ \\
\hline 2. & $\begin{array}{l}\text { Общность } \\
\text { ценностей }\end{array}$ & $\begin{array}{l}\text { Сотрудник знает и разделяет } \\
\text { подлинные ценности первых лиц и } \\
\text { акционеров компании, а также их } \\
\text { видение будущего }\end{array}$ & $\begin{array}{lr}\text { Как правило, это самая } \\
\text { непростая } \\
\text { поскольку эти ценности } \\
\text { должны быть искренними, } \\
\text { позитивными } \\
\begin{array}{l}\text { способными вдохновить } \\
\text { остальных сотрудников }\end{array}\end{array}$ \\
\hline 3. & Оптимизм & $\begin{array}{l}\text { Сотрудник верит в будущее своей } \\
\text { компании, уверен в правильности } \\
\text { выбранного руководством пути и } \\
\text { его способность успешно пройти } \\
\text { по этому пути }\end{array}$ & $\begin{array}{l}\text { Необходимо } \\
\text { прогрессивных наличие } \\
\text { будущего, пбразов } \\
\text { новому качеству жизни }\end{array}$ \\
\hline 4. & $\begin{array}{l}\text { Демократический } \\
\text { стиль руководства }\end{array}$ & 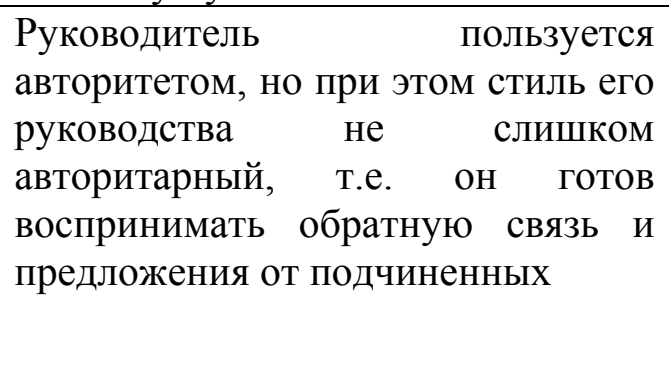 & $\begin{array}{l}\text { Однако слишком большое } \\
\text { делегиро-вание } \\
\text { полномочий, отсутствие } \\
\text { контроля за реализацией } \\
\text { решений руководителя } \\
\text { вызывает хаос и не } \\
\text { способствует } \\
\text { эффективному внедрению }\end{array}$ \\
\hline
\end{tabular}




\begin{tabular}{|c|c|c|c|}
\hline № & Фактор & $\begin{array}{c}\text { Характер и способ влияния } \\
\text { (проявления) }\end{array}$ & Комментарии \\
\hline & & & инноваций \\
\hline 5. & $\begin{array}{l}\text { Налаженный } \\
\text { канал связи и } \\
\text { степень } \\
\text { взаимопонимания } \\
\text { с начальником }\end{array}$ & \begin{tabular}{lcr} 
Сотрудник & имеет & \multicolumn{2}{c}{ возможность } \\
быстро и легко довести & свои \\
инновационные & идеи & до \\
руководства компании &
\end{tabular} & $\begin{array}{l}\text { Большое значение имеет } \\
\text { культура коммуникаций, } \\
\text { когда } \\
\text { оперативно реагирует на } \\
\text { письма и о обращения } \\
\text { подчиненных, а принятые } \\
\text { на совещаниях решения } \\
\text { действительно } \\
\text { контролируются } \\
\text { внедряются }\end{array}$ \\
\hline 6. & $\begin{array}{l}\text { Благоприятная } \\
\text { атмосфера }\end{array}$ & $\begin{array}{l}\text { Компания имеет динамичную, } \\
\text { жизнерадостную, профессионально } \\
\text { компетентную атмосферу }\end{array}$ & $\begin{array}{lr}\text { Важно } & \text { отсутствие } \\
\text { противостояния } & \text { между } \\
\text { основными } & \\
\text { функциональными } & \text { и } \\
\text { обслуживающими } \\
\text { подразделениями } \\
\end{array}$ \\
\hline 7. & $\begin{array}{l}\text { Взаимопомощь, } \\
\text { сотрудничество }\end{array}$ & $\begin{array}{l}\text { В компании практикуется } \\
\text { наставничество, есть возможность } \\
\text { посоветоваться с более опытными } \\
\text { коллегами, обсудить свои идеи и } \\
\text { найти помощь в процессе их } \\
\text { реализации }\end{array}$ & $\begin{array}{l}\text { Приветствуется } \\
\text { неформальное лидерство, } \\
\text { в том случае, если } \\
\text { неформальный } \\
\text { находится видер } \\
\begin{array}{l}\text { отношениях } \\
\text { руководством }\end{array} \\
\end{array}$ \\
\hline 8. & $\begin{array}{lr}\text { Проектно- } \\
\text { командный } \\
\text { подход } \\
\text { реализации } \\
\text { развития }\end{array}$ & $\begin{array}{l}\text { В компании развита командная } \\
\text { деятельность, существует практика } \\
\text { организации команд под } \\
\text { конкретные проекты, при этом в } \\
\text { зависимости от целей различных } \\
\text { проектов состав команд изменяется }\end{array}$ & \\
\hline 9. & $\begin{array}{l}\text { Ограничение } \\
\text { личной } \\
\text { конкуренции }\end{array}$ & $\begin{array}{l}\text { В компании не развивается и не } \\
\text { приветствуется } \\
\text { конкуренция, ночная } \\
\text { командное соперничество }\end{array}$ & \\
\hline 10. & $\begin{array}{l}\text { Самоуважение, } \\
\text { самореализация }\end{array}$ & $\begin{array}{l}\text { Сотрудник ощущает свою } \\
\text { значимость, он чувствует, что с его } \\
\text { мнением считаются, к нему } \\
\text { прислушиваются, руководитель } \\
\text { проявляет к нему личный интерес. } \\
\text { Руководство заботится об условиях } \\
\text { труда сотрудников }\end{array}$ & $\begin{array}{l}\text { Необходимо проведение } \\
\text { мероприятий, на которых } \\
\text { сотрудники могли бы } \\
\text { высказать свое мнение и } \\
\text { внести предложения по } \\
\text { улучшению деятельности }\end{array}$ \\
\hline 11. & $\begin{array}{l}\text { Отсутствие } \\
\text { вертикальных } \\
\text { функциональных } \\
\text { перегородок }\end{array}$ & $\begin{array}{l}\text { В компании хорошо налажены } \\
\text { горизонтальные } \\
\text { потоки, имеет } \\
\text { уровень место высокий } \\
\text { культуры }\end{array}$ & $\begin{array}{lr}\text { При этом } & \text { существует } \\
\text { минимальное } & \text { количество } \\
\text { утомительной } & \text { бюрократии } \\
\text { при } & \text { получении } \\
\text { согласований } & \text { руководства } \\
\end{array}$ \\
\hline 12. & Справедливость & $\begin{array}{l}\text { Сотрудник-инициатор инноваций } \\
\text { уверен, что в случае успешного } \\
\text { внедрения его предложений его } \\
\text { приоритет не будет затушеван и он }\end{array}$ & \\
\hline
\end{tabular}




\begin{tabular}{|c|c|l|l|}
\hline № & \multicolumn{1}{|c|}{ Фактор } & \multicolumn{1}{|c|}{$\begin{array}{c}\text { Характер и способ влияния } \\
\text { (проявления) }\end{array}$} & Комментарии \\
\hline 13. & Ответственность & $\begin{array}{l}\text { получит адекватное материальное } \\
\text { вознаграждение }\end{array}$ & $\begin{array}{l}\text { Сотрудники привыкли не только } \\
\text { участвовать, но и брать на себя } \\
\text { ответственность }\end{array}$ \\
\hline
\end{tabular}

Второй этап исследования (2011-2012) заключался в анкетном опросе собственников и менеджеров российских компаний - слушателей программ MBA о важности данных факторов корпоративной культуры для стимулирования инновационной активности сотрудников и формирования инновационного климата в компании. Основными задачами исследования являлись:

1. Выявление наиболее значимых факторов, влияющих на эффективность инновационной деятельности и затрат.

2. Проверка гипотез о связи приоритетов в выборе факторов корпоративной культуры с демографическими характеристиками участников опроса и их компаний.

3. Изучение возможности уменьшения количества факторов на основе устойчивой корреляции в ответах участников.

В исследовании приняли участие представители 104 компаний из различных регионов РФ. Распределение компаний по размеру бизнеса приведено в таблице 2.

Таблица 2

\begin{tabular}{|l|l|l|}
\hline Крупные компании & Средние компании & Мелкие компании \\
\hline 44 & 28 & 22 \\
\hline
\end{tabular}

В демографической части анкеты был также сформулирован вопрос о сфере деятельности (виде бизнеса) компании, при этом участники опроса могли выбрать несколько сфер деятельности своих компаний. Результаты распределения по видам бизнеса приведены в таблице 3.

Таблица 3

\begin{tabular}{|l|l|l|l|}
\hline Производство & Услуги & Торговля & Финансы \\
\hline 40 & 44 & 20 & 11 \\
\hline
\end{tabular}

В таблице 4 приведено распределение участников опроса по должностному уровню в их компаниях:

\begin{tabular}{|c|c|c|}
\hline $\begin{array}{l}\text { Менеджеры } \\
\text { специалисты }\end{array}$ & Топ-менеджеры & Собственники \\
\hline 67 & 16 & 17 \\
\hline
\end{tabular}

Для решения первой задачи исследования каждому участнику опроса было предложено отметить те факторы корпоративной культуры, которые, по его мнению, действительно существенно влияют на инновационную активность в организации. Выделение фактора в одной анкете приносило участнику один балл. В результате обработки всех анкет баллы по каждому фактору были просуммированы. Результаты приведены в таблице 5.

Таблица 5

\begin{tabular}{|l|l|l|l|l|l|l|l|l|l|l|l|l|l|}
\hline $\begin{array}{l}\text { № } \\
\text { факта }\end{array}$ & 1 & 2 & 3 & 4 & 5 & 6 & 7 & 8 & 9 & 10 & 11 & 12 & 13 \\
\hline Баллы & $\mathbf{7 2}$ & 42 & 53 & 60 & 61 & $\mathbf{6 8}$ & 63 & 43 & 13 & 61 & 24 & $\mathbf{6 9}$ & 64 \\
\hline
\end{tabular}


Таким образом, все факторы корпоративной культуры можно условно разделить на четыре группы. В первую группу вошли наиболее значимые факторы. Наибольшее количество баллов получил фактор «Прозрачность целей», в котором подразумевается понимание сотрудниками миссии компании, смысла ее деятельности с точки зрения общественной пользы. Такой результат позволяет сделать вывод о том, что стремление к росту осмысленности и общественной пользы своей деятельности является главным стимулом инновационного поведения. В группу сильно значимых факторов вошли также: благоприятная атмосфера (компания имеет динамичную, жизнерадостную, профессионально-компетентную атмосферу) и справедливость (убежденность сотрудника в признании своего вклада и получении адекватного материального вознаграждения). Последний фактор явно указывает на основной барьер инновационной активности в российском бизнесе.

Во вторую группу вошли факторы достаточно высокой значимости: демократический стиль руководства, налаженный канал связи с начальником и взаимопомощь, сотрудничество, а также умение принимать ответственность.

В третью группу можно отнести факторы средней значимости: оптимизм, общность целей, проектно-командный подход к решению задач.

Наконец, к четвертой группе относятся факторы низкой значимости. Это ограничение личной конкуренции и налаженность горизонтальных информационных потоков. Необходимо отметить, что оба эти фактора отмечаются как весьма существенные в работах западных исследователей. Можно говорить об их недостаточной осознанности в российском деловом сообществе.

Участниками опроса была предоставлена возможность расширить перечень факторов корпоративной культуры, влияющих на эффективность инновационной деятельности. Были дополнительно предложены следующие факторы:

- готовность сотрудников получать новые знания и совершенствоваться индивидуально и вместе с другими сотрудниками;

- наличие обратной связи при предложении новых идей;

- поощрение личного профессионального роста сотрудников;

- возможность продвижения по карьерной лестнице в короткие сроки.

Для решения задачи исследования связи приоритетов в выборе ключевых характеристик инновационной корпоративной культуры с демографическими характеристиками компаний и респондентов было сформулировано несколько базовых (нулевых) гипотез:

- выбор ключевых факторов корпоративной культуры инновационной организации не зависит от сферы деятельности компаний;

- выбор ключевых факторов корпоративной культуры инновационной организации не зависит от размера бизнеса компании;

- выбор ключевых факторов корпоративной культуры инновационной организации не зависит от должностного уровня респондента.

Проверка гипотез была осуществлена на основе применения статистического аппарата в программе Statistica (Елисеева, 2004). Использован метод сравнения частот выбора факторов в общей выборки опроса с частотами выбора соответствующих факторов в более узкой демографической выборке.

Рассмотрим подробно, например, проверку базовой гипотезы о независимости выбора от размера компании для фактора 13- (умение принимать ответственность).

Для проведения статистического анализа компании разбиты на две более крупные группы: крупные компании - 44; мелкие и средние компании - 50.

Относительную частоту упоминания фактора в основной выборке обозначим $m / n$, где $m$ - количество анкет с упоминанием данного фактора, $n$ - общее количество анкет. Для фактора «ответственность» $m=64, n=104$. 
Относительную частоту упоминания фактора в изучаемой подвыборке обозначим $m_{0} / n_{0}$. В конкретном случае рассматривается подвыборка мелких и средних компаний, $n_{0}=50, m_{0}=$ 23 (число упоминаний фактора «ответственность» среди представителей мелких и средних компаний).

В качестве критерия проверки базовой (нулевой гипотезы) применяется сравнение величины

$$
Z=\frac{\frac{m}{n}-\frac{m_{0}}{n_{0}}}{\sqrt{P(1-P)\left(\frac{1}{n}+\frac{1}{n_{0}}\right)}}
$$

где:

$$
P=\frac{m+m_{0}}{n+n_{0}}
$$

с критериальным значением функции Лапласа при уровне значимости 0,95. В случае превышения значения $Z$ критериального значения нулевая гипотеза отклоняется.

Для нашего конкретного примера величина $p=0,565, Z=1,82$.

Значение функции Лапласа при 95\%-ной достоверности равно 1,96. Следовательно, величина $Z$ не превышает критериального значения, и принимается основная гипотеза, то есть гипотеза о независимости выбора фактора «ответственность» от размера компаний.

Аналогичные результаты были получены по всем факторам корпоративной культуры. Таким образом, можно уверенно утверждать, что выбор приоритетов среди факторов корпоративной культуры, влияющих на инновационную активность, не зависит от размера компании.

Сходные результаты были получены при проверке первой гипотезы: можно утверждать, что приоритеты в выборе инновационных факторов корпоративной культуры не зависят от сферы деятельности (вида бизнеса компании). При проверке гипотезы все компании были разбиты на две укрупненные выборки: производственные и непроизводственные компании.

При проверке гипотезы о зависимости приоритетов в выборе инновационных факторов корпоративной культуры от должностного уровня участников опроса все респонденты были разделены на две укрупненные группы: 1) менеджеры и специалисты, 2) топ-менеджеры и собственники бизнеса.

Гипотеза о наличии зависимости в выборе от должностного уровня не подтвердилась ни по одному из факторов корпоративной культуры. Таким образом, по результатам нашего пилотного исследования можно говорить о том, что выбор приоритетных факторов инновационной корпоративной культуры не зависит ни от каких демографических характеристик компаний и опрашиваемых.

Третья задача исследования заключалась в проверке зависимостей в выборе отдельных факторов корпоративной культуры и возможном снижении размерности факторного пространства. Решение данной задачи проведено на основе метода главных компонентов факторного анализа данных с применением программы Statistica (Гмурман, 2003).

Суть анализа заключалась в разбиении факторов на более крупные группы компоненты (Factor), внутри которых располагаются факторы, чаще всего встречающиеся одновременно.

Наиболее обоснованное разложение было получено для четырех компонентов. Расчет факторных нагрузок, т.е. значений коэффициентов корреляции каждого из исходных признаков с каждым компонентом, приведен в таблице 6. 


\begin{tabular}{|l|l|l|l|l|}
\hline & Factor 1 & Factor 2 & Factor 3 & Factor 4 \\
\hline Прозрачность целей & $-0,00688$ & $0,7167 *$ & 0,216865 & 0,121021 \\
\hline Общность ценностей & 0,100058 & $0,681764 *$ & 0,0183 & 0,093553 \\
\hline Оптимизм & 0,333419 & $0,54183 *$ & 0,291435 & $-0,30321$ \\
\hline $\begin{array}{l}\text { Демократический стиль } \\
\text { руководства }\end{array}$ & $0,797482 *$ & $-0,11767$ & 0,121938 & 0,022833 \\
\hline Налаженный канал связи & 0,41341 & 0,018383 & 0,467962 & 0,314049 \\
\hline Благоприятная атмосфера & $-0,04185$ & 0,098933 & $0,809042 *$ & $-0,01197$ \\
\hline $\begin{array}{l}\text { Взаимопомощь, } \\
\text { сотрудничество }\end{array}$ & $0,690968 *$ & 0,287297 & 0,016404 & 0,096427 \\
\hline $\begin{array}{l}\text { Проектно-командный подход } \\
\text { к реализации задач развития }\end{array}$ & 0,247828 & $-0,108$ & $0,550444 *$ & 0,211489 \\
\hline $\begin{array}{l}\text { Ограничение личной } \\
\text { конкуренции }\end{array}$ & 0,09638 & $-0,05$ & 0,202308 & $0,734471 *$ \\
\hline $\begin{array}{l}\text { Самоуважение, } \\
\text { самореализация }\end{array}$ & 0,046222 & 0,292233 & $0,629863 *$ & $-0,04455$ \\
\hline $\begin{array}{l}\text { Отстуствие вертикальных } \\
\text { функцональных перегородок }\end{array}$ & 0,070652 & 0,398717 & $-0,10187$ & $0,66808 *$ \\
\hline Справедливость & $0,515071 *$ & 0,374301 & 0,162526 & 0,077274 \\
\hline Ответственность & 0,169445 & 0,285088 & 0,415945 & 0,037719 \\
\hline
\end{tabular}

Выбирая максимальное значение в каждой строке таблице, обозначенное *, можно определить, к какому компоненту следует отнести данный фактор.

Таким образом, можно разделить факторы на четыре группы совместного выбора:

1. «Демократический стиль руководства», «Взаимопомощь сотрудничество», «Справедливость».

2. «Прозрачность целей», «общность ценностей», «оптимизм».

3. «Благоприятная атмосфера», «Проектно-командный подход к реализации задач развития», «Самоуважение и самореализация».

4. «Отсутствие функциональных перегородок» и «Ограничение личной конкуренции».

Факторы «Налаженный канал связи и степень взаимопонимания с начальником» и «Ответственность» нельзя четко отнести ни к одной из групп укрупненных групп.

Можно сказать, что в первую группу входят факторы, характеризующие отношение сотрудников с руководством, во вторую - миссию и видение, в третью - отношение с коллегами, в четвертую - организационную структуру. Это позволяет предположить возможность уменьшения количества факторов при проведении более масштабного исследования.

Подводя итоги исследования, хотелось бы остановиться на способах влияния наиболее значимых факторов на инновационную активность, инновационный капитал и, как следствие, на рост стоимости компании. Наше исследование подтверждает мнение зарубежных и российских исследователей о том, что миссия (цель организации с точки зрения общественной пользы) и видение (способы достижения данной цели) являются вдохновляющим фактором для команды инновационного бизнеса и условием приложения сверхординарных усилий, необходимых для продвижения инноваций (Шейн, 2002; Спивак, 2010). Общее видение, обладающее мотивирующим потенциалом, позволяет добиться существенного роста инновационного капитала, который выражается в увеличении количества и качества технологических и организационных ноу-хау, новых предпринимательских концепций. Благоприятная деловая атмосфера является важным фактором формирования способности организации к достижению договоренности и сотрудничеству. Она повышает качество отношений между руководством компании и персоналом, внутри компании, отношений с контрагентами, собственниками, государством. Можно сказать, что благоприятная атмосфера вносит вклад в активы качества отношений, 
которые являются компонентом стоимости компании.

\section{Список литературы}

1. Байбурина Э.Р. Методы анализа интеллектуального капитала для современного устойчивого развития компании// Корпоративные финансы. 2007. № 3, т. 3. С. 85-101.

2. Гмурман В.Е. Теория вероятностей и математическая статистика. М.: Высшая школа, 2003.

3. Елисеева И.И., Юзбашев М.М. Общая теория статистики. Глава 11. М.: Финансы и статистика, 2004.

4. Ивашковская И.В. Моделирование стоимости компании. Стратегическая ответственность советов директоров. Глава 4. М.: Инфра-М, 2009.

5. Колобов А.А. Экономика инновационной деятельности наукоемких предприятий. Глава 3. М.:МГТУ им. Баумана, 2007.

6. Ляпина С.В., Первакова Е.Е., Снесарева Е.В. Корпоративная культура и инновации в компании.// Инновации. 2009. № 12, т. 134. С. 45-54.

7. Первакова Е.Е. Влияние корпоративной культуры на производительность труда и эффективность бизнеса. Глава 4. М.: Макс Пресс, 2012.

8. Спивак В.А. Образы инновационной организации // Сборник докладов по итогам международной научно-практической конференции, Москва, 29 марта - 09 апреля 2010 г.

9. Шейн Э. Организационная структура и лидерство. СПб.: Питер, 2002.

10. Bessant, J. (2009), Innovation. Chapter 8. New Jork: DK Publishing.

11. Cooke, R.A., Szumal, J.L. (2000), Using the Organizational Culture Inventory to understand the operating cultures of organizations. // Handbook of organizational culture and climate, 4 (2000) 1032-1045.

12. Hannan, M., Freeman, J. (1984), Structural Inertia and Organization Change, American Sociological Review, 49 (1984) 214-226.

13. Heskett, J. (2012), The Culture Cycle. How to shape unseen forse that transforms performance. Chapter 4, New Jersey: FT press.

14. Janis, I. (1982), Groupthink (2nd ed.) Boston: Houghton Mifflin.

15. Jaruzelski, B., Loehr, J., Holman, R. (2011), The Global Innovation 1000. Why Culture is Key?: Strategy + business (Booz \& Company).

16. Jaskyte, K. (2004), Transformational Leadership, Organizational Culture, and Innovativeness in Nonprofit Organizations, Nonprofit Management \& Leadership, 2(15 (2004).

17. King, N., Anderson, N. (1995), Innovation and Change in Organization. New York: Routledge.

18. Shultz, T. (1968), Human Capital in: The International Encyclopedia of the Social Sciences. N.Y., Vol 6.

19. Steers, R.M., Sanchez-Runde, C.J., Nardon, L (2010), Management Across Culture. Challenges and Strategy. Chapter 1 Cambridge: Cambridge University Press. 